Área Abierta. Revista de comunicación

audiovisual y publicitaria

ISSN: 2530-7592

\title{
¿Me da una Mirinda?” Constantes en el cine de Álex de la Iglesia
}

\author{
Pablo García Ureña ${ }^{1}$
}

Recibido: 6 de marzo de 2016 / Aceptado: 1 de octubre de 2016

Resumen. Este artículo analiza el primer cortometraje de Álex de la Iglesia, Mirindas asesinas (1991), señalando algunas de las constantes de su filmografía. Especialmente cómo su lectura sobre la sociedad española y su relación con el pasado, así como su inmersión en la sociedad del espectáculo, están presentes en este trabajo seminal. Del mismo modo ocurre con la manera de evidenciar o desvelar esas temáticas, lo que se hace no de forma directa, sino a partir de un cine de entretenimiento, haciendo uso de un particular sentido del humor y utilizando para ello la caricatura, el esperpento y la violencia.

Palabras clave: Álex de la Iglesia; crítica social; director; violencia; cortometraje

\section{[en] Can I Have a Mirinda? Constants in the Cinema of Álex de la Iglesia}

\begin{abstract}
The present paper analyzes the first short film by Alex de la Iglesia, Mirindas asesinas (1991), identifying the constants of his filmography. This includes how his reading of the Spanish society and its relation to the past, as well as its immersion in the society of spectacle, are present from this seminal work onward. That is also the case with respect to the way of highlighting these topics, which is not done overtly, but through entertainment film and making use of a peculiar sense of humor: the resources employed include caricature, esperpento, and violence.
\end{abstract}

Keywords: Álex de la Iglesia; Social Criticism; Filmmaker; Violence; Short Film

Sumario. 1. Introducción. 2. Un purgatorio castizo. 3. Compañeros de viaje. 4. Conclusiones. 5. Bibliografía.

Cómo citar: García Ureña, P. (2017) “Me da una Mirinda?” Constantes en el cine de Álex de la Iglesia, en Área Abierta. Revista de comunicación audiovisual y publicitaria 17 (2), 199-212. http:// dx.doi.org/10.5209/ARAB.52042

\section{Introducción}

Deduciendo podemos concluir que cualquier cosa tiene dos aspectos: uno corriente, el que vemos casi siempre y que ven los hombres en general, y el otro espectral o metafísico que sólo pocos individuos pueden ver en momentos de clarividencia...

Giorgio de Chirico, Sobre el arte metafisico, 1919

$1 \quad$ Universidad Complutense de Madrid (España)

pgurena@ucm.es 
Mirindas asesinas (1991), rotundo primer cortometraje de Álex de la Iglesia, sienta las bases de lo que serán las obsesiones o lugares comunes de la filmografía del director vasco. Es un cortometraje en el que ya se encuentra su inseparable Jorge Guerricaecheverría, coguionista de buena parte de sus películas, y que permitió a Álex de la Iglesia dar el salto al largometraje tras ser visto por los hermanos Almodóvar ${ }^{2}$, quienes a su vez iniciaron la andadura de su productora El Deseo más allá de sus propias películas con la producción de Acción mutante. Antes de Mirindas asesinas, Álex de la Iglesia venía de hacer decorados para ETB y de colaborar con Pablo Berger como director artístico en el cortometraje Mamá (1988). Fue la marcha de Berger a Nueva York lo que empujó a Álex de la Iglesia a la dirección del cortometraje: "Hice Mirindas asesinas, pero si hubiera estado Pablo en España supongo que hubiera seguido haciendo decorados. Se aceleraron las cosas"3. La oportunidad se materializó a partir de la realización de los decorados para un cortometraje de Iñaki Arteta que se retrasó, lo que llevó a Álex de la Iglesia a plantearse la posibilidad de aprovechar los mismos. Y así lo hizo: en cuestión de días escribió el guion con Guerricaecheverría y formó el equipo, endeudándose para financiar el proyecto 4 .

Como se irá mostrando a continuación, el eco de Mirindas asesinas se encuentra presente, con mayor o menor intensidad, en toda su obra, desde su primer largometraje, Acción mutante (1993), hasta su última película hasta la fecha, Mi gran noche (2015). Obsesiones que en su cine son dirigidas a desvelar o desenmascarar algunas constantes de la España posterior a la Transición, películas — salvo Perdita Durango (1997) y Los crímenes de Oxford (2008) — , que radiografían con crudeza la sociedad española, aunque siempre con un particular sentido del humor, poniendo en evidencia las perversiones de un país que, narcotizado tras las muerte de Franco, se abalanzó, fascinado, sobre los brazos de la posmodernidad. En la obra de Álex de la Iglesia van de la mano la sociedad española seducida por el capitalismo, individualista, inmersa en el espectáculo, y aquella otra que resucita una España negra y brutal de tiempos pretéritos para sugerir que, de hecho, se trata de dos caras de la misma moneda. Película tras película, y también con sus dos novelas publicadas hasta la fecha, Payasos en la lavadora (1997) y Recuérdame que te odie (2014), insiste en retratar una y otra vez esa sociedad en la ha crecido y vive tratando de desenmascarar rabiosamente la grotesca realidad que se esconde tras tanto artificio. Y lo hace desde su interior, desde un cine supuestamente de entretenimiento que muestra de forma oblicua su desengaño o suspicacia ante esa cultura espectacular.

A este respecto se pueden establecer dos cuestiones, tal y como plantea Moreiras:

¿Se puede pensar y dar sentido a la contemporaneidad desde una posición espectacular o, por el contrario, esta posición lleva consigo la ausencia de pensamiento? ¿Se producen prácticas culturales que, desde sus marcos textuales o fílmicos, tienen como objetivo reflexionar críticamente sobre esta cultura espectacular? ${ }^{5}$

2 "Hace dos años, una amiga le hizo llegar a Almodóvar Mirindas asesinas y el esbozo de guion de Acción mutante. Le gustó, y me llamó". En Muñoz, D. (1992): "Almodóvar produce monstruos," El País, Madrid (26-05).

3 Crespo, B. (2005: 95): "Álex contra el doctor Tedio". En Cine fantástico y de terror español 1984-2004, San Sebastián: Donostia Zinemaldía.

4 Angulo y Santamaría (2012: 32).

5 Moreiras (2002: 67). 
Los estudios de esta autora sobre Álex de la Iglesia dan respuesta afirmativa a este caso concreto y, tal y como considera el propio director, "si os fijáis, todas mis películas tienen un claro componente político [...] a mí siempre me ha interesado

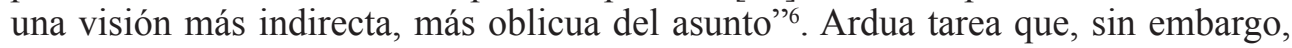
aborda con un humor negro, negrísimo. Asumiendo que es imposible escapar de esa cultura del espectáculo, plantea su reflexión y su crítica desde ella. En palabras de Bourriaud, "el artista habita las circunstancias que el presente le ofrece para transformar el contexto de su vida [...] La modernidad se prolonga hoy en la práctica del bricolaje y del reciclaje de lo cultural"7.

Como señalan Buse, Triana Toribio y Willis con respecto al primer largometraje de De La Iglesia, siendo en nuestra opinión extensible a Mirindas asesinas, "While de Socialist government of post-Franco Spain was intent on 'cleaning up the image' (lavarle la cara) of the nation, Acción mutante, steeped in the desencanto, resists any such temptation"8.

Frente a la narrativa del consenso posfranquista aparece paralelamente otra lectura heterodoxa, la del desencanto, para Alberto Medina,

En ocasiones resistencia radical al poder, en otras evidente cómplice a éste; actitud heroica o cobardemente pasiva y resignada; llanto inútil por una identidad siempre ya perdida o enfermedad necesaria en el proceso de metamorfosis a un sujeto puesto al día9 .

En el caso de De La Iglesia, como se pretende demostrar en este texto, no se trata del habitual distanciamiento respecto al pasado asociado al desencanto, tan propio de la posmodernidad española de los años 80, sino que, como indica Medina respecto a ciertos autores - Goytisolo, Saura, Chavarri o Panero-, plantea "una cercanía excesiva y dolorosa, la cercanía del melancólico al objeto de la pérdida, la interrogación sobre lo irrecuperable en el espacio del yo" ${ }^{10}$.

\section{Un purgatorio castizo}

Con Mirindas asesinas nos situamos en un bar fantasmagórico, extraño, con unos expresionistas contrastes de luces y sombras y un humo espeso, denso, que rememora a aquellos clubes del film noir, pero pasado por un ligero tamiz de casticismo, como evidencia la omnipresente tragaperras de los bares españoles. Según Álex de la Iglesia:

Los decorados que hicimos eran una locura, y además no eran los ideales para el corto de Arteta. Era lo que nos apetecía hacer, una especie de local gótico, antes de Batman, obsesionados con la arquitectura de Eiffel. Allí metimos las reproducciones de De Chirico. Mirindas asesinas fue también producto de la lectura de textos dadaístas, que nos influyeron en esa época. Una mezcla de nuestras paranoias infantiles y Tristan Tzara ${ }^{11}$.

6 Angulo y Santamaría (2012: 161)

7 Bourriaud (2008: 12).

8 Buse, Triana Toribio, \& Willis (2007: 51).

9 Medina Domínguez (2001: 68)

10 Ibídem, p. 80.

11 Crespo, B. (2005: 94). 
Efectivamente, el decorado produce un intenso extrañamiento con su ambiente espectral o fantasmagórico que otorga al bar un aura de espacio de tránsito, casi de purgatorio. En las paredes del local nos encontramos con la reproducción de dos cuadros del pintor Giorgio de Chirico, Misterio y melancolía de una calle (1914) y Las musas inquietantes (1918) que no hacen sino enfatizar esa atmósfera. De Chirico, visualiza en su obra a través de espacios arquitectónicos, sombras y objetos solitarios insólitos la sensación de melancólico extrañamiento. Los personajes que van apareciendo por el bar y desapareciendo — más bien falleciendo- de él no hacen más que acrecentar la sensación de que nos encontramos ante una suerte de no-lugar en el que no hay espacio para personalizaciones. El bar podría presentarse como metáfora de la España posfranquista, sobre todo del periodo que va de 1982 a 1995, calificado por Muniesa como un espacio de tiempo en el que se camina "de la euforia a la perplejidad" 12 . Camino en cuyos márgenes se van acumulando aquellos personajes marginados de esa euforia y que pueblan la cinematografía del realizador vasco. Como veremos, estos dos estados de ánimo, la euforia y la perplejidad tornada en locura, están muy presentes en Mirindas asesinas. Debemos recordar en este punto la fecha de realización del cortometraje que nos ocupa, 1991, punto crítico de esa dimensión espectacular en la que buena parte de la sociedad española vivía embriagada ante el siguiente año, el de los festejos: Juegos Olímpicos en Barcelona, Exposición Universal en Sevilla, Capitalidad Cultural Europea en Madrid y Año Jacobeo en Santiago de Compostela; mientras, se sucedían los casos de corrupción, el índice de desempleo era el más elevado de la Comunidad Europea y la violencia terrorista continuaba.

La historia del cortometraje de Álex de la Iglesia es sencilla: una sintonía radiofónica informa de que un asesino en serie -interpretado por Álex Angulo-, anda suelto. Presumiblemente este decide hacer un alto en su camino en el local en cuestión para deleitarse con un refresco, una "mirinda" que, como otras bebidas de burbujas, apela a una infancia irrecuperable, a una suerte de paraíso perdido. Es conveniente detenernos a contextualizar el citado refresco. Esta bebida gaseosa fue creada en España en 1960 y su nombre, proveniente del esperanto, significa "admirable, maravilloso". Muy publicitada durante la década de los sesenta y setenta, bien podría ser considerada como símbolo del desarrollismo y de la difusión de los modos de consumo capitalista en España, dentro de la euforia económica y la seducción mediática de aquellos años ${ }^{13}$. Como veremos, por muchas mirindas que beba el protagonista, no conseguirá saciar su insatisfacción, la frustración de un ideal roto, irrealizable, prometido constantemente por los medios de comunicación de masas.

Tras beberse el refresco, el tubular killer ${ }^{14}$, tal y como se le menciona en los créditos finales, da rienda suelta a sus manías. Obsesiones vinculadas con la teatralización del lenguaje, con expresiones ritualizadas del tipo de "¿me da una mirinda?" o "¿tiene hora?". En las conversaciones que establece con el resto de personajes del bar, rompe el principio de cooperación que rige una conversación. Para él la tensión entre el significado literal (lo codificado) y el significado figurado

12 Muniesa, B. (2005: 173-267).

13 Nos referimos al llamado milagro económico español que se produce entre los años 1959 y 1973.

14 Tubular en el sentido de circular, cíclico, pues como veremos el asesino repite un mismo modus operandi con los personajes con los que se relaciona. 
(lo transmitido) es máxima, y cuando el interlocutor participa de estas expresiones eludiendo la pura literalidad, desata toda su ira contra el personaje en cuestión.

Para el apocado asesino, que el camarero pretenda cobrarle el refresco cuando le había preguntado que si se lo daba, o que otro cliente le dijera la hora en lugar de responder afirmativa o negativamente a la pregunta de "itiene hora?”, supone algo sencillamente superior a sus fuerzas ${ }^{15}$, tornándose ese carácter tímido y reprimido mostrado en un primer momento en ira incontrolable ${ }^{16}$. Como podremos comprobar, las similitudes con Humpty Dumpty (Zanco Panco), el personaje de Alicia a través del espejo de Lewis Carroll, son evidentes:

— ¿Qué edad me dijiste que tenías?

Alicia hizo un pequeño cálculo y contestó:

— Siete años y seis meses.

— ¡Te equivocaste!, exclamó Zanco Panco, muy ufano.

— ¡Nunca me dijiste nada semejante!

— Pensé que lo que usted quería preguntarme era más bien “¿qué edad tiene?”,

explicó Alicia.

— Si hubiera querido decir eso, lo habría dicho, ¡ea!, replicó Zanco Panco ${ }^{17}$.

Cabe preguntarnos por los motivos de esta susceptibilidad, cuáles son las razones que desatan un carácter desquiciado ante cierto protocolo asumido socialmente. Podríamos relacionar esta suspicacia con la teatralización de la vida social y política en los años 80, en la que algunos individuos aislados no disfrutan, o no quieren hacerlo, de un buen papel y no asumen determinados modos de conducta. Un espectáculo asumido con rapidez en España, ya que "el ideal de mayoría de edad formulado a la caída del franquismo se formula en una dimensión espectacular. Se trata de escenificar la modernidad, su ideal emancipador, en el contexto y con las reglas de la "sociedad del espectáculo""18.

Estos parias sociales a los que aludíamos, son por otra parte, habituales en el cine de Álex de la Iglesia: incomprendidos, paletos, freaks..., todo un surtido de personajes situados en los márgenes del gran espectáculo. Desde Mirindas asesinas hasta la reciente Mi gran noche, nos encontramos dentro de la filmografía de Álex de la Iglesia con una galería de personajes inadaptados, desencantados o insatisfechos ante una sociedad consumista y represiva que les promete un ideal y no produce más que decepciones y por extensión, situaciones dramáticas ${ }^{19}$. Estos antihéroes terminan desatando su furia contra una sociedad que seduce, promete y decepciona, dando paso a una violencia profundamente carnavalesca:

15 Álex Angulo interpretaría un personaje similar en la segunda película de Álex de la Iglesia, El día de la bestia. Ambos personajes se caracterizan por la timidez e incomprensión que experimentan y que les empuja a reaccionar violentamente.

16 También podemos observar este arquetipo en Nino, el personaje interpretado por Santiago Segura en Muertos de Risa (1999); o en Javier Granados, el payaso triste de Carlos Areces de Balada triste de trompeta (2010).

17 Carroll, L. (2010: 147-148)

18 Medina Domínguez (2001: 62).

19 Uno de los ejemplos más notables dentro de la filmografía de Álex de la Iglesia es el de La chispa de la vida (2011), donde precisamente sitúa a uno de esos personajes arrasados por unas complicadas circunstancias económicas y personales como espectáculo en sí mismo. 
En Mirindas están ya los payasos y la tragedia, manifiesta en este caso en el personaje de Saturnino García, que sufre tremendamente durante todo el corto. Al final de este se escucha asimismo un tema musical muy parecido al de Balada. ${ }^{20}$

\section{Compañeros de viaje}

Como evidencia el aspecto del bar al final del cortometraje, son varias las personas que tienen la fatalidad de tropezar en el camino del asesino, aunque sólo se recoge el encuentro que se produce con cuatro de ellas. Las dos primeras, ya presentes en el bar al hacer su entrada en escena nuestro psicópata, son el camarero y otro cliente, este último interpretado por Saturnino García ${ }^{21}$, que acababa de pedir la cuenta y pretendía marcharse. El camarero es el primer interlocutor y también el primero en ser asesinado (fig. 1).

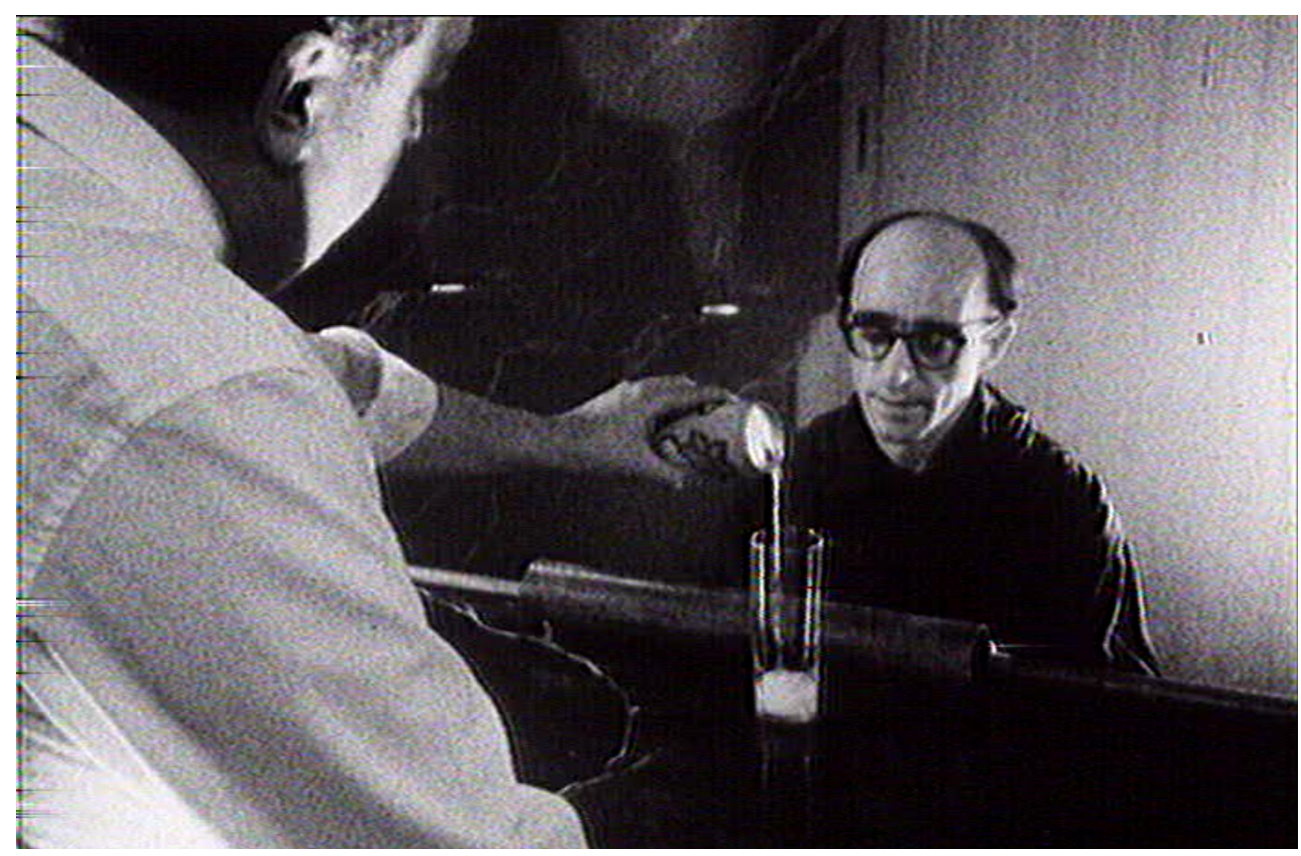

Figura 1. El actor Saturnino García interpreta al cliente

20 Angulo y Santamaría (2012: 143)

21 Este actor protagonizaría Justino, un asesino de la tercera edad (1994), película dirigida por Santiago Aguilar y Luis Guridi con un papel similar al de Álex Angulo en Mirindas asesinas en cuanto la marginación que como jubilado sufre por parte de la sociedad y su violenta respuesta. 
Como se ha apuntado anteriormente, son las obsesiones con el lenguaje y sus convencionalismos las que empujan a cometer este asesinato cuando el camarero trata de cobrar el refresco:

— Son 120.

¿120 qué?

- 120 pesetas, la mirinda, que no me la ha pagado.

— ¿Y por qué habría de pagarla?

_ ¿Te estás quedando conmigo?

- No no no, pero yo le he dicho que me diera una mirinda, no que se la pagaba.

— Bueno, son 120, ¿las tienes, o qué?

_ ¿Pero no me entiende? No me entiende, yo le digo que me la dé, y me la da. ¿Y ahora me la quiere cobrar? Siempre la misma historia.

Esa incomprensión es el motor argumental, el detonante de la frustración del personaje, como recuerda Álex de la Iglesia, "nos interesaba mucho el metalenguaje, que concretamos en la imagen del loco educado. Y, claro, teníamos ese punto pedante de estudiantes universitarios que estábamos enganchados a la escuela de Franckfurt"22.

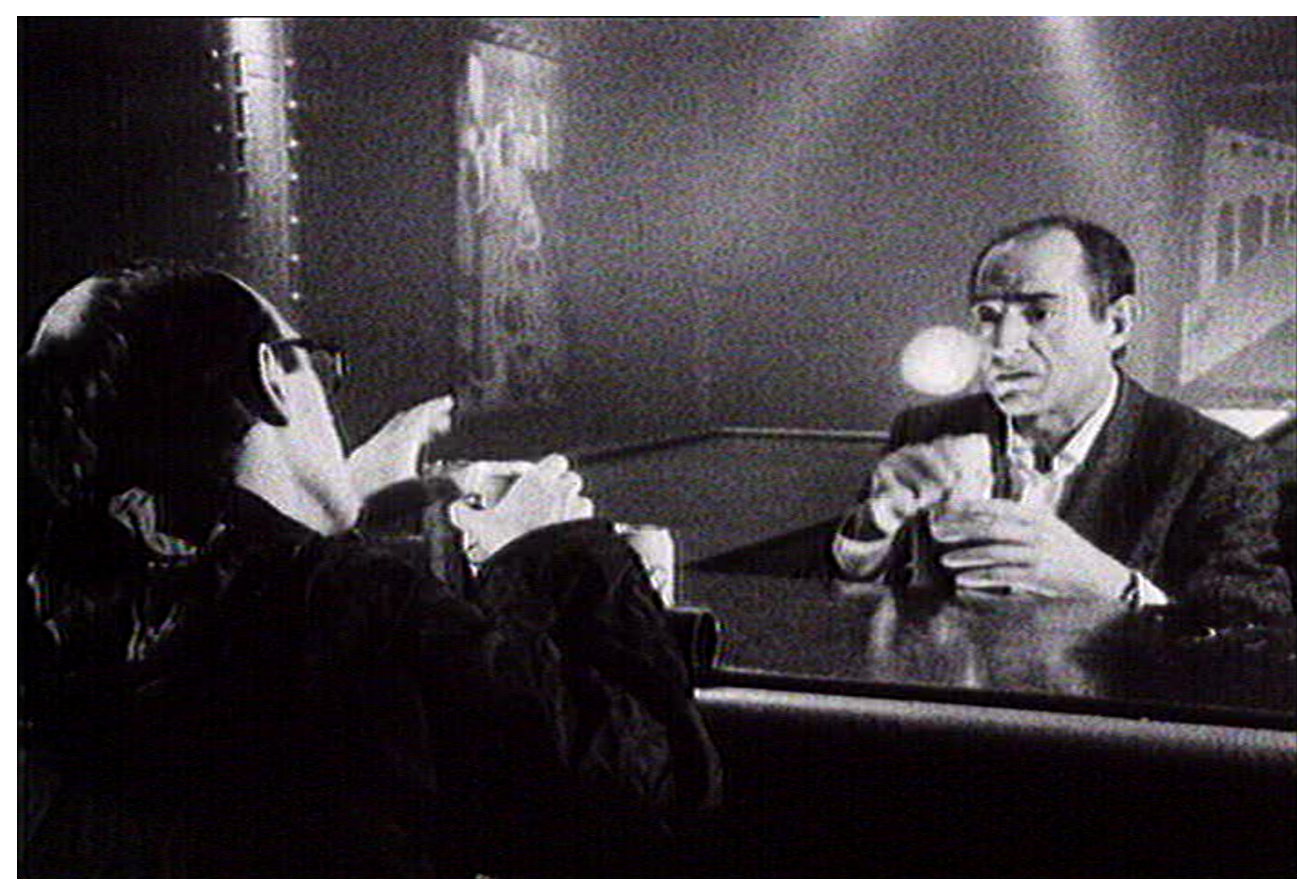

Figura 2. El cliente es obligado a ejercer de camarero 
Tras la muerte del camarero, nuestro tubular killer vuelve a disfrutar de su mirinda como si nada hubiera pasado, comentando al aterrado personaje interpretado por Saturnino García que "no hay nada como una mirinda [...] pero fría de la nevera, no de hielos, que luego se queda muy aguada" y pidiéndole que le sirva otra, impidiendo así su marcha y obligándole a ejercer de camarero (fig. 2).

Este detalle se convertiría en algo habitual en la filmografía de Álex de la Iglesia; ese particular contrapunto entre violencia, trivialidad del lenguaje y humor negro tan característico del director ${ }^{23}$. Como observan en este sentido Buse, Triana-Toribio y Willis, "relevant in relation to De la Iglesia are Luis García Berlanga and Fernando Fernán-Gómez, whose Brand of black comedy known as esperpento De la Iglesia updates and most typically fuses with elements of horror"24.

Después de que ambos personajes consuman varias mirindas, hace su entrada en escena un nuevo personaje, que podríamos considerar representante de aquel sector de la sociedad triunfante, moderno, que parece disfrutar de las mieles del éxito. Este nuevo interlocutor, joven y bien vestido, entra confiado en el establecimiento pidiendo una Coca-Cola y línea para hablar por teléfono, sin prestar la menor atención al cadáver del anterior camarero que yace sobre la barra. Para acentuar aún más el significado de este personaje, de la imagen que transmite, se le sitúa justo delante de un póster de gran tamaño de una portada de la revista Vogue con el rostro de Isabella Rosellini ${ }^{25}$, verdadero icono referencial de belleza sobre aquellos años. En cuanto a la mítica revista, al igual que la publicidad de refrescos como la mirinda, actúa como un instrumento del biopoder de modelación social. Se trata de una "socialidad" que, parafraseando a Baudrillard, "opera no ya por la ley y la represión, sino por la infiltración de los modelos, no ya por la violencia, sino por la persuasión-disuasión" ${ }^{\prime 26}$. Evidentemente este personaje atrae la atención del asesino, quien automáticamente entabla conversación con él:

— ¿Tienes hora?

— Las seis y media pasadas.

No es necesario recoger el resto de la conversación, pues podemos deducir la conclusión de la misma, habida cuenta de las particularidades manías de nuestro protagonista con el lenguaje. De nuevo, este haría uso de su ametralladora para acribillar al joven, con un ensañamiento que no había mostrado con el camarero; imágenes que se complementan con una Isabella Rossellini salpicada de sangre (fig. 3).

23 Características comunes a otro director que también comenzó su carrera en la década de los 90, Quentin Tarantino, y con el que comparte una mutua admiración.

24 Buse, Triana Toribio, \& Willis (2007: 4).

25 Se trata del número 20 de Vogue España de 1989. El póster presente en los decorados del cortometraje es una reproducción exacta de dicha portada, conservando incluso el código de barras de la revista en la misma disposición.

26 Baudrillard, J. (2012: 157). 


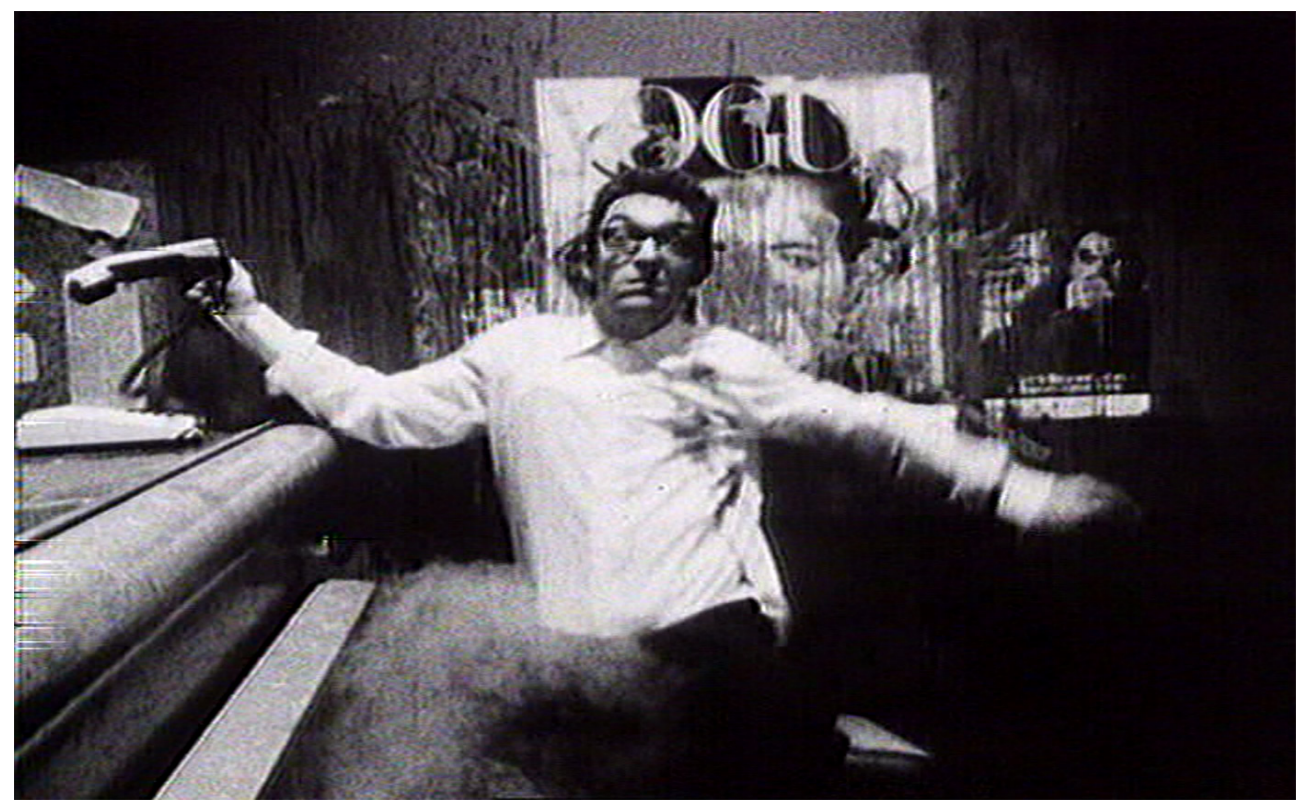

Figura 3. El cartel de Isabella Rossellini salpicado de sangre

Con este asesinato, el tubular killer arremete contra el simulacro de la experiencia, contra la transformación fetichista y perversa de lo real. Iniciaba así Álex de la Iglesia la que sería una de sus críticas constantes a lo largo de su filmografía, dirigida hacia los mass media y a aquella clase media alta consumista, superficial y frívola. Esta crítica la encontramos de manera clara y más desarrollada en su primera película, Acción mutante y en otras posteriores como Crimen Ferpecto (2004) o La chispa de la vida (2011). Como indican Jordan y Morgan-Tamosunas sobre Acción mutante, "offers a bitting critique of 1980s yuppies and designer Socialists, their tastes, values and styles, which are mercilessly mocked and subverted"27.

Tras descargar su ira, el tubular killer continúa consumiendo mirindas, como evidencia la barra repleta de botes y vasos vacíos, mientras Saturnino García, asumiendo las funciones del camarero, limpia la barra aplicadamente como si los cadáveres que supuestamente acompañan al consumo de mirindas no tuvieran que ver con él. Es entonces cuando aparece el cuarto y último personaje de la historia interpretado por Ramón Barea, representante en esta ocasión de una España rancia, anclada en el pasado. Al entrar en el local, pide al camarero un gin-kas mientras se dirige a la barra ${ }^{28}$ sorteando un campo de cadáveres desperdigados por el suelo sin inmutarse lo más mínimo por lo que hay a su alrededor, hasta fijar su atención en un televisor (fig. 4). 


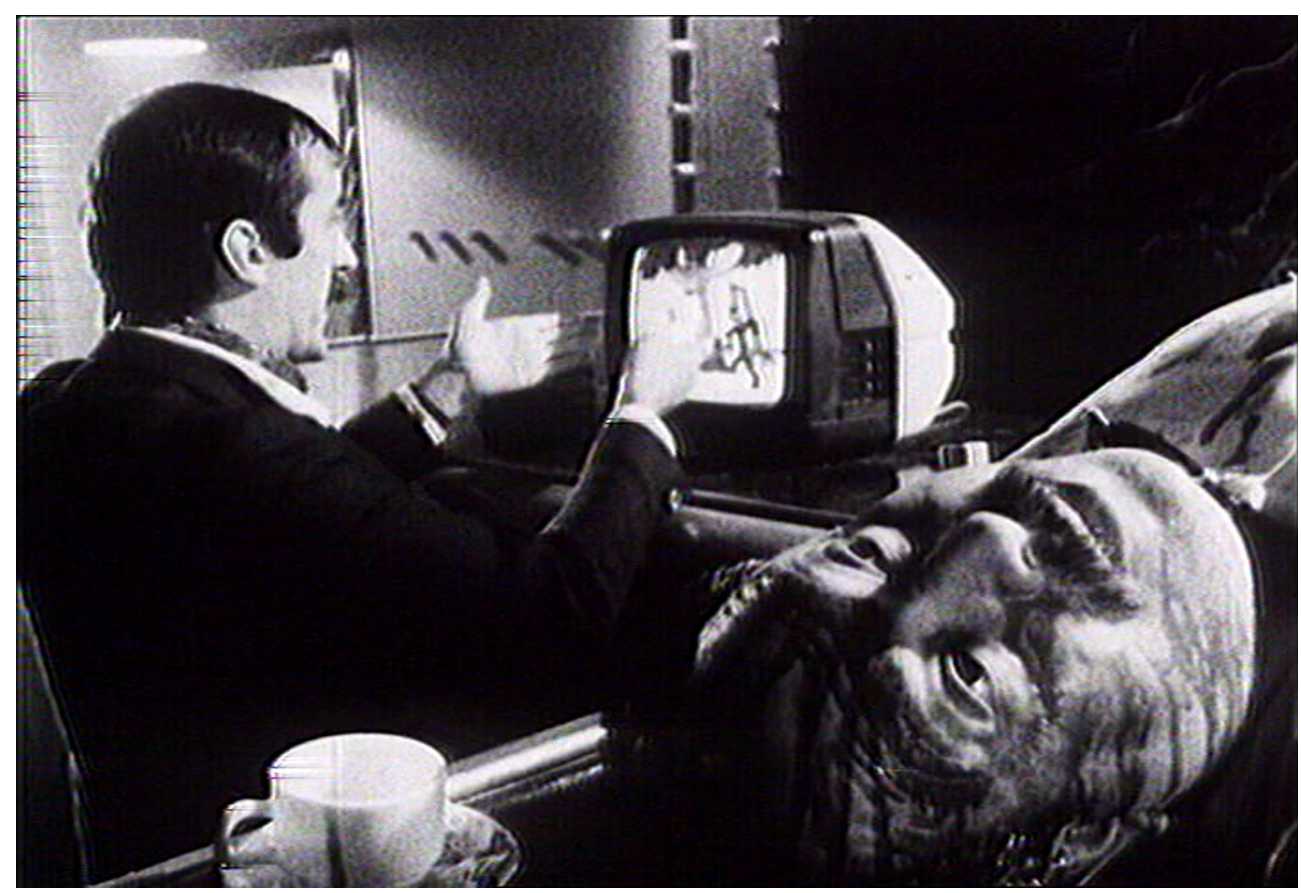

Figura 4. El último cliente fija su atención en la televisión

Este personaje incide y subraya el individualismo que caracterizaba al anterior cliente, ajenos ambos a lo que ocurre a su alrededor, acentuado por un Saturnino García que también parece haber olvidado — solo momentáneamente- lo ocurrido. Como hemos indicado, este último cliente queda absorto ante una televisión situada en la barra ${ }^{29}$, justo al lado del cadáver del camarero, cambiando de canal hasta que da con la retransmisión de una corrida de toros ${ }^{30}$, encabezada por Paco Camino, torero de éxito que desarrolló su carrera durante los años 60 y 70.

Si como decíamos el anterior cliente encarnaba esa sociedad seducida por los modos de comportamiento y consumo capitalistas, frívola, individualista, pretendidamente moderna, tan característica de la década de los años 80, este último personaje representa en apariencia y actitud la continuidad o pervivencia de modelos procedentes del franquismo. Este arquetipo es, al igual que el representado por el anterior cliente, habitual en la filmografía de Álex de la Iglesia. Como apunta Cristina Moreiras en relación a La comunidad (Alex de la Iglesia, 2000), y que se puede hacer

29 El poder hipnótico de la televisión es tratado en varias ocasiones por De la Iglesia, como es el caso de Acción Mutante (1993), El día de la bestia (1995), y de manera más explícita en Muertos de risa (1999) o Mi gran noche (2015).

30 Antes de dar con la corrida de toros, este personaje sintoniza momentáneamente los dibujos animados de $L a$ gata loca, emitidos en España por TVE en los años 60 y también cargados de violencia. Es la historia de un amor no correspondido entre Krazy Kat (la gata loca) y el ratón Ignatz, que rechaza con un ladrillazo las declaraciones de amor de la gata, provocando por el contrario que aumente el enamoramiento de esta. 
extensible a buena parte de la obra de De la Iglesia, "sin hablar de la relación entre franquismo y democracia, pone en escena ejemplarmente la continuidad entre las temporalidades que ocupan ambos momentos y ambos aparatos ideológicos" 31 .

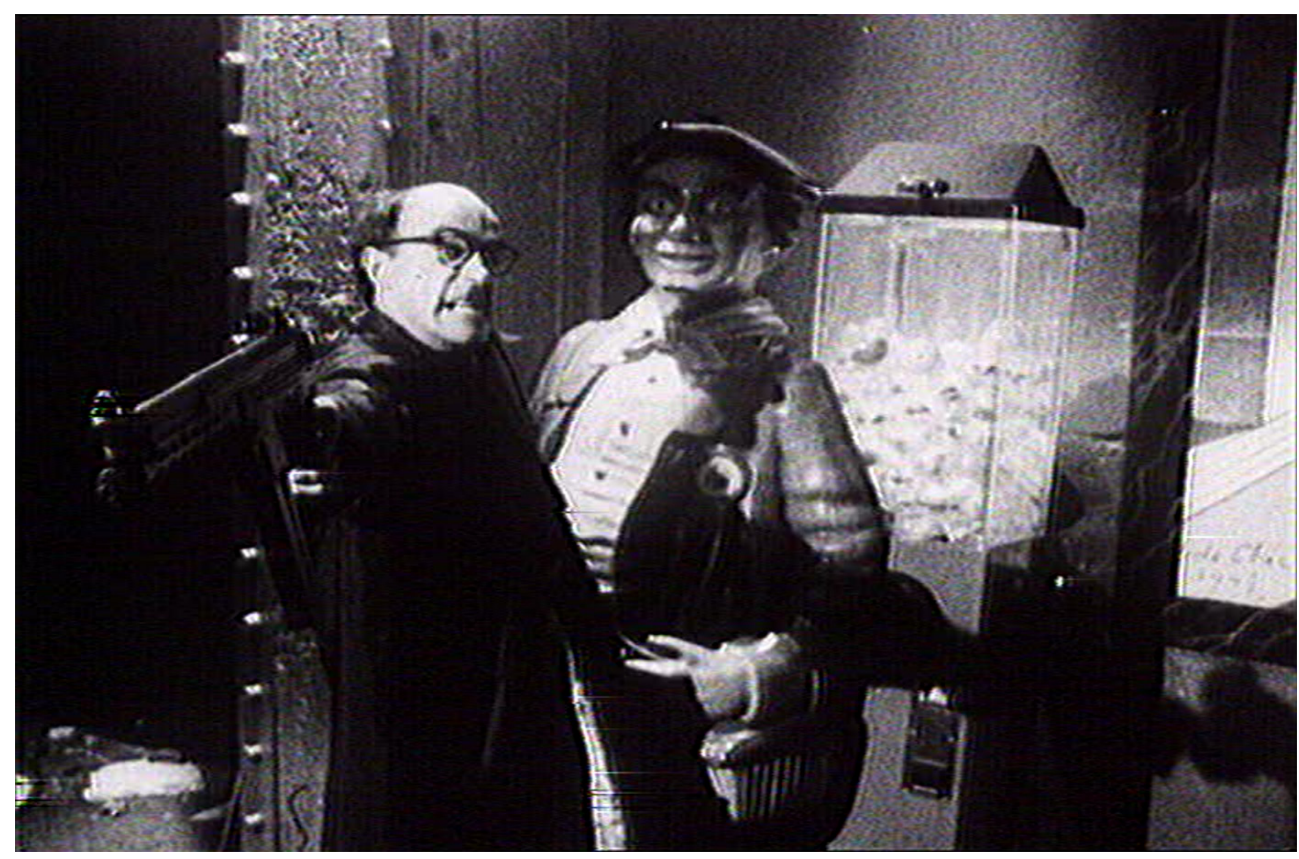

Figura 5. La figura de Olentzero

El personaje interpretado por Álex Angulo, molesto por los efusivos comentarios del nuevo cliente ante la corrida de toros, se dirige al mismo con la intención de ponerlo a prueba con varias preguntas. Sin embargo, estas preguntas no surten efecto alguno, puesto que esta figura del pasado responde afirmativa o negativamente sin participar de las convenciones del lenguaje que había llevado a la muerte a los personajes anteriores. El deseo del tubular killer de dar salida a su ira se vería frustrado, al fracasar en su último intento con la pregunta que formula metralleta en mano, pidiendo una moneda para la máquina expendedora de bolas sorpresa presidida por la figura del Olentzero, carbonero mitológico perteneciente a la tradición vasca y cuyo origen se vincula a las celebraciones del solsticio de invierno anteriores a la expansión del cristianismo por esta región (fig. 5).

Este carbonero borrachín, glotón y desharrapado representó con su quema la destrucción del tiempo pasado y la renovación ${ }^{32}$. Una renovación que en este caso

31 Moreiras, C. (2008: 376).

32 Respecto al Olentzero, se han ido configurando distintas versiones, desde algunas que lo describen como un ogro hasta otras que lo hacen como si de una suerte de Papá Noel fuera. Para profundizar en el mito, véase Martínez Soto, C. (2009). "Olentzero, evolución de un mito". Antzina: revista de genealogía vasca e historia local, 33-37, y Satrústegui, J. M. (1988). “Olentzero: estudio del personaje mítico vasco”, Cuadernos de etnología y 
parece imposible, pues tras responder negativamente a la pregunta este último cliente se marcha como había entrado, tropezando con los cadáveres que va encontrando a su paso, acentuando el absurdo al señalar al cliente-camarero que le apuntara en su cuenta la consumición. Situaciones rocambolescas como esta, cercanas al absurdo, son constantes en la filmografía de Álex de la Iglesia: "Sí, en Mirindas ya estaba explicitada mi fascinación por el absurdo ${ }^{33}$ ".

Deteniéndonos en el campo de cadáveres en el que se convierte el local y en la actitud de los clientes ante el mismo, caben varias reflexiones. En primer lugar, debemos recordar cómo los dos últimos clientes, que habíamos identificado como representantes de una España volcada en la posmodernidad y otra continuación de las estructuras predemocráticas, se mantienen ajenos a los muertos acumulados en los márgenes, en la cuneta, a pesar de que literalmente tropiecen con ellos. La presencia de estos cadáveres es anulada, reprimida, para evitar la mirada en el espejo y la confrontación con el pasado y la violencia que lo envuelve. Un pasado oculto tras "un pacto del olvido" que "permitió a la sociedad española pasar de una brutal dictadura lateralmente moderna y, por tanto, políticamente aislada y obsoleta, al circuito económico, cultural y político que caracteriza al paradigma posmoderno que nos ha tocado vivir" 34 . Sobre ello volvería a insistir el director vasco en películas posteriores como Muertos de risa o Balada triste de trompeta. Respecto a la contraposición entre esa España franquista y la europea que muestra, De la Iglesia señala que "efectivamente, es la misma España, donde hay un problema que todavía no se ha resuelto" 35 . En segundo lugar, es significativo que, de esos dos clientes en cuestión, es el que encarna la continuidad con tiempos pretéritos el que resulta indemne a la prueba del tubular killer, mientras que el yuppie es asesinado con gran ensañamiento, mostrando la supervivencia o perduración de modelos y estructuras del pasado.

La frustración del asesino tras el recién intento fallido por descargar su ira alcanza su punto máximo al comprobar que su vaso de mirinda se había calentado. El clientecamarero, consciente de que solo queda él en el local, comienza a llorar desencajado mientras el tubular killer le pregunta si tiene hora (fig. 6). El absurdo se acentúa más si cabe cuando, tras formular su pregunta y no recibir respuesta, el tubular killer se despereza y se remanga levemente para mirar su reloj, para comunicarle amigablemente al camarero: "Bueno, me voy a marchar. Se ha hecho tarde. Bueno, nos vemos", dice.

Es el personaje interpretado por Saturnino García el que, testigo de todo lo sucedido y al contrario de los otros dos clientes a los que hemos hecho referencia, se atreve o es forzado finalmente a mirar al sinsentido que le rodea - recordemos que llegó a estar limpiando la barra haciendo caso omiso al cadáver del verdadero camarero- Incapaz de asimilar esa mirada al Otro, se quiebra en llanto desconsolado ante el horror que implica la apertura a una realidad que se muestra apocalíptica y que cómodamente es obviada.

etnografia de Navarra, núm. 51, 5-22.

33 Angulo y Santamaría (2012: 143).

34 Vilarós, T. (1998: 16).

35 Ibidem, p. 221. 


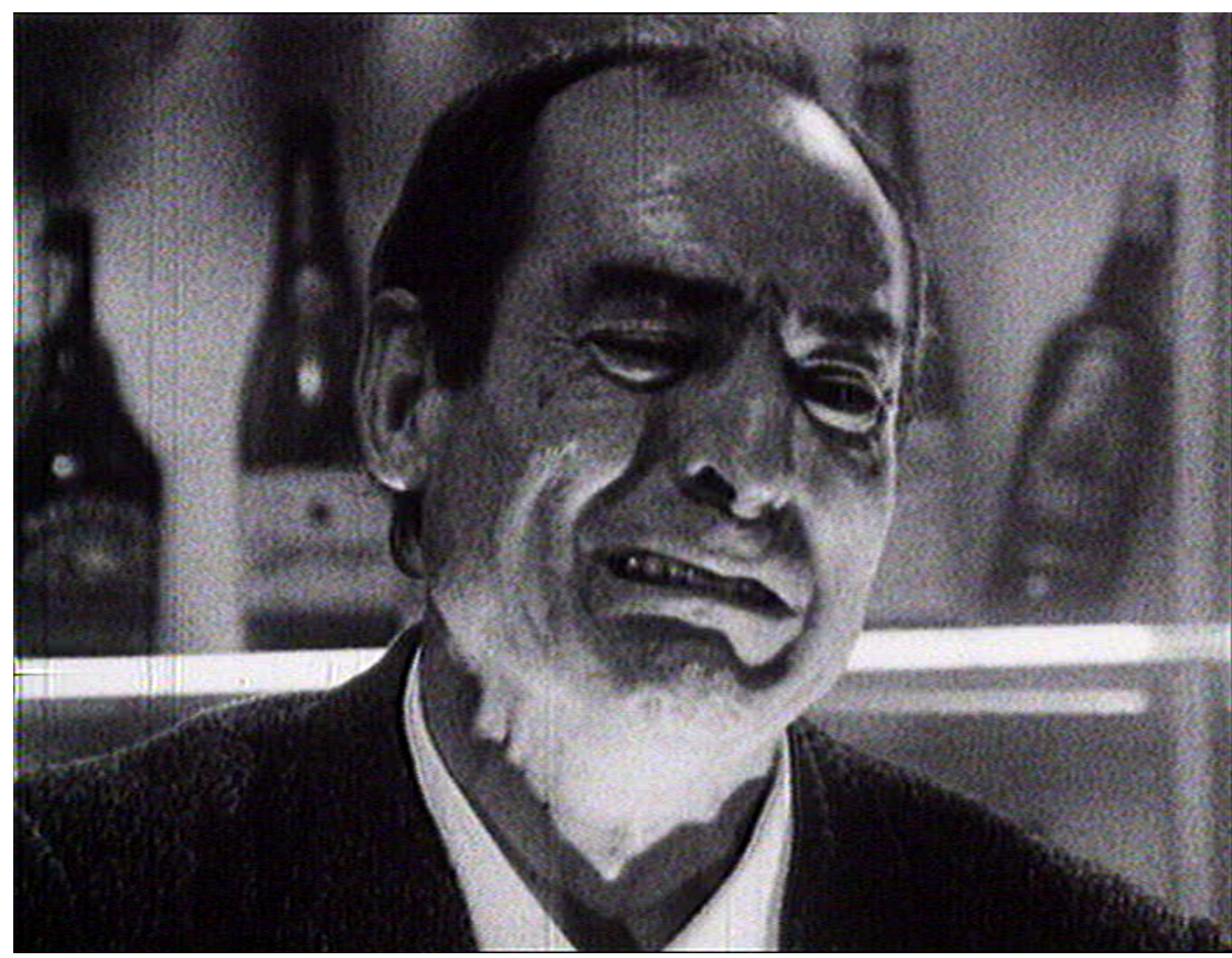

Figura 6. El cliente-camarero finalmente rompe a llorar

\section{Conclusiones}

En los doce minutos de duración de Mirindas asesinas, quedan expuestas las obsesiones de Álex de la Iglesia como director, sobre las que ha ido insistiendo constantemente a lo largo de su filmografía con diversos enfoques, aunque siempre bajo el velo del espectáculo, del cine de entretenimiento.

Queremos insistir en la idea de cómo dentro de esa cultura espectacular se pueden generar obras que, como en el caso de Álex de la Iglesia y desde un cine de género reivindicado repetidas veces por él, ofrezcan una reflexión profunda sobre el contexto social, político y económico en el que han sido generadas. En el caso que motiva este estudio, una reflexión generada en todo momento a partir del humor y la hipérbole, tanto en personajes como en situaciones violentas, tratando de evidenciar desde la sátira aquello que preocupa u obsesiona al director vasco. Es esta una constante que, quizá a excepción de Perdita Durango (1997) y Los crímenes de Oxford (2008) - más evidente en esta última-, se convierte en seña característica de identidad o autoría a partir de Mirindas asesinas.

Como se ha ido desgranando a lo largo de este texto, la sociedad española y su relación con el pasado, así como su inmersión en la sociedad del espectáculo con su radical individualismo, es mostrada poniendo en evidencia sus deformaciones 
y perversiones, su violencia implícita, soterrada, mediante otra violencia explícita, carnavalesca, casi redentora, por parte de esos personajes rotos omnipresentes en la obra del director vasco. La confrontación entre este tipo de personajes que no responden al canon marcado por los medios de comunicación y aquellos otros que en apariencia se podrían definir como triunfadores, iniciada en Mirindas asesinas, es recurrente dentro de la filmografía de Álex de la Iglesia.

\section{Bibliografía}

Angulo, J. y Santamaría, A. (2012). Álex de la Iglesia. La pasión de rodar. San Sebastián: Fundación Filmoteca Vasca.

Baudrillard, J. (2012). Cultura y simulacro. Barcelona: Kairós.

Bourriaud, N. (2008). Estética relacional. Buenos Aires: Adriana Hidalgo.

Buse, P., Triana Toribio, N., \& Willis, A. (2007). The Cinema of Álex de la Iglesia. Manchester: Manchester University Press.

Carroll, L. (2010). Alicia a través del espejo. Madrid: Alianza Editorial.

Jordan, B. \& Morgan-Tamosunas, R. (2001). Contemporary Spanish Cinema. Manchester: Manchester University Press.

Martínez Soto, C. (2009). “Olentzero, evolución de un mito”. Antzina: revista de genealogía vasca e historia local, 33-37.

Medina Domínguez, A. (2001). Exorcismos de la memoria. Políticas y poéticas de la melancolía en la España de la transición. Madrid: Ediciones Libertarias.

Moreiras, C. (2002). Cultura herida. Literatura y cine en la España democrática. Madrid: Ediciones Libertarias.

- (2008) "Nuevas fundaciones: Temporalidad e historia en La comunidad de Álex de la Iglesia", $M L N$, núm. 123, 374-395.

Muniesa, B. (2005). Dictadura y Transición. La España lampedusiana, vol. II. Barcelona: Universitat de Barcelona.

Pérez, N. (2010). "La intertextualidad en el cine de Álex de la Iglesia: el caso del cómic". Fotocinema, Revista Cientifica de Cine y Fotografía, núm. 1, 39-73.

Rivero, M. (2015). "El esperpento en el cine de Álex de la Iglesia", Fonseca, Journal of Communication, núm. 10, 360-392.

Satrústegui, J. M. (1988). “Olentzero: estudio del personaje mítico vasco”, Cuadernos de Etnología y Etnografía de Navarra, núm. 51, 5-22.

Subirats, E. (2001). Culturas virtuales. Madrid: Biblioteca Nueva.

Triana Toribio, N., \& Triana-Toribo, M. (2004). "Esto no es un juego, es Acción mutante: The Provocations of Álex de la Iglesia". Journal of Iberian and Latin American Studies, vol. 10, 9-22.

Vilarós, T. (1998). El mono del desencanto. Una crítica cultural de la transición española (1973-1993). Madrid: Siglo XXI.

VV.AA. (2005). Cine fantástico y de terror español 1984-2004. San Sebastián: Donostia Zinemaldia. 